\title{
Os editais do Literatura em Minha Casa: sobre leitura, literatura e leitores
}

\author{
THE EDICTS FROM LITERATURE AT HOME: \\ ON READING, LITERATURE AND READERS
}

Moama Lacerda MARQUES *

Resumo: Inserido nos estudos sobre História da Leitura, o presente artigo objetiva analisar as concepções de leitura, de literatura e de leitor que os editais de elaboração dos livros do Literatura em minha casa, programa de promoção do livro e da leitura executado pelo governo federal entre os anos de 2002 e 2004, deixam entrever. Em termos de fundamentação teórica, nos valemos de discussões pautadas nos estudos de Roger Chartier, Luiz Percival Leme de Britto e Márcia Abreu.

Palavras-chave: Literatura em minha casa; História da Leitura; Editais.

Abstract: Inserted in the History of Reading studies, this paper aims at analyzing the conceptions of reading, literature and reader present in the edicts for book production Literature at home, a federal government program that promoted books and reading from 2002 to 2004. In what concerns theory, we take hand of the discussions based on the studies by Roger Chartier, Luiz Percival Leme de Britto and Márcia Abreu.

Key-words: Literature at home; History of Reading; Edicts.

\section{Sobre o "Literatura em minha casa": uma introdução}

Para o historiador Roger Chartier (1999, p. 8),"o livro sempre visou instaurar uma ordem; fosse a ordem de sua decifração, a ordem no interior da qual ele deve ser compreendido ou, ainda, a ordem desejada pela autoridade que o encomendou ou permitiu a sua

\footnotetext{
* Doutoranda em Letras pela Universidade Federal da Paraíba. Contato: moamalorena@hotmail.com.
} 
publicação." No caso dos livros produzidos para o Literatura em minha casa, é na entrância desta última ordem, a da autoridade que os encomendou, que analisaremos as concepções de leitura, de literatura e de leitor que estão subjacentes à formação das coleções encomendadas e distribuídas pelo MEC.

O LMC,${ }^{2}$ idealizado e executado pelo PNBE/MEC (Programa Nacional Biblioteca da Escola/Ministério da Educação), distribuiu livros de literatura para os alunos da rede pública de todo o país durante os anos de 2002, 2003 e 2004. Tendo sido considerado inovador, pelo fato de entregar os livros diretamente aos alunos e por trabalhar com coleções criadas especialmente para o programa, e não compostas por livros que já circulavam no mercado, o texto de seus editais e do prefácio de seus livros, sempre escritos por pessoas de renome na área da leitura/literatura, deixam entrever as concepções de leitura, de literatura e de leitor existentes no programa.

Os editais, por serem a fonte mais rica na busca pelas concepções citadas, especialmente seus anexos, nos quais estão explicitados os critérios de avaliação e seleção das coleções e as especificações técnicas mínimas que elas deveriam conter, foram selecionados como nosso objeto de análise.

\section{Sobre leitura, literatura e leitores: analisando os editais}

Em primeiro lugar, o que esses editais revelam é o cuidado que o MEC teve em demonstrar credibilidade e honestidade no trato com as editoras, que poderiam concorrer com apenas uma coleção. Havia a etapa da pré-inscrição, que correspondia ao cadastramento para participação, e a da inscrição, que seria a entrega efetiva das coleções. Estas, formadas por cinco gêneros diferentes, deveriam ter um único titular e ser entregues já em edição finalizada. Só poderiam concorrer coleções que não contivessem obras do PNBE do ano anterior e que fossem elaboradas por um único titular de direito editorial; outra exigência dizia respeito à quantidade mínima e máxima de páginas por

${ }^{2}$ Ao longo do artigo utilizaremos LMC para designar Literatura em minha casa. 
coleção e por volume, bem como a exigência de que o projeto gráfico, ou seja, a apresentação física da obra, caracterizasse os volumes como uma coleção.

O que essas condições de participação já demonstram é a consciência que o MEC tinha da importância da materialidade do livro, da sua condição como objeto. $O$ primeiro anexo, por exemplo, especifica a análise de estrutura editorial, ditando, minuciosamente, os elementos que deveriam constar na primeira capa, na quarta capa, na folha de rosto e no verso da folha de rosto. Já a segunda e a terceira capas deveriam ser reservadas a possíveis mensagens, de autoria do próprio MEC, relativas ao programa. Caso um dos volumes integrantes da coleção não estivesse em acordo com as especificações constantes no referido anexo, a coleção toda seria excluída do processo.

Ampliando algumas imposições de ordem física, temos, no anexo III, as especificações técnicas mínimas para cada um dos volumes que compõem as coleções; especificações que detalham o formato dos livros, o material da capa e o tipo de impressão desta, bem como o tipo e o tamanho de sua fonte; especificações em relação ao miolo, incluindo o tipo de papel e a alvura e a opacidade mínima permitidas, e, finalmente, algumas imposições referentes ao acabamento dos livros; imposições estas que eram diferenciadas para os livros com mais de 96 páginas e que se referiam, por exemplo, ao tipo de lombada e ao grampeamento.

Dispomos, em última análise, das considerações expostas no anexo II dos editais porque são elas que melhor revelam os objetivos do LMC e as motivações que justificaram essa iniciativa do MEC. É especificamente nesse espaço do edital que vemos destrinchados os critérios de avaliação e de seleção das coleções; critérios referentes ao projeto editorial, à temática e à textualidade, à seleção de títulos e autores, ao projeto gráfico e às ilustrações.

O referido anexo é iniciado com uma apresentação que deixa exposta a finalidade do LMC, bem como as razões que o justificariam. A finalidade seria selecionar e distribuir coleções para alunos da rede pública; nesse momento, não é anunciado o objeto dessas coleções, o tipo de texto que elas apresentariam, apenas a série que teria os alunos contemplados. Já as razões para tal distribuição mostram uma nítida preocupação com uma formação de leitor que se confunde com a 
formação do próprio cidadão, um leitor-cidadão. A leitura, sob esse aspecto, não acarretaria apenas transformações intelectuais e de efeito estético sobre o leitor, mas contribuiria para transformações práticas. Através da leitura de textos literários e de textos de reflexão sobre a realidade brasileira, o sujeito-leitor, caracterizado como alguém cujas condições de acesso ao livro, tanto fora quanto dentro da escola, são extremamente limitadas, seria possibilitado, através do desenvolvimento intelectual e do letramento, de participar da sociedade letrada. E tanto a leitura de textos literários quanto a de textos sobre a realidade brasileira provocaria essa inserção, apesar da importância da literatura se sobrepor, mesmo que isso se revele de maneira sutil, não apenas pela excelência quantitativa que se concede ao texto literário, mas também pela qualitativa, através do elogio aos seus efeitos no leitor e da crença de sua importância para a preservação do patrimônio cultural brasileiro.

Dessa forma, o governo acreditava estar realizando uma iniciativa de caráter político-pedagógico, uma iniciativa importante para a democratização do acesso ao saber e à cultura, até mesmo porque a doação aos alunos permitiria inserir, como uma espécie de "prêmioextra", a família no usufruto desses bens culturais, o que revela uma preocupação com a circulação dos livros; preocupação esta enfatizada nos editais pelo desejo explícito do MEC de que se formassem círculos de leitura através de trocas de textos. Vejamos um trecho do edital que confirma essas nossas considerações:

Uma iniciativa dessa natureza representa para milhões de brasileiros - crianças, jovens e adultos - a primeira oportunidade de ter contato com obras de literatura e de reflexão sobre a realidade brasileira. Neste sentido, são evidentes seu caráter pedagógico e sua importância como elemento de disseminação de cultura. Além disso, possibilita a criação de círculos de leitura, por meio de trocas e intercâmbio de textos. (BRASIL, 2003, p. 17 - grifo nosso)

O referido trecho aponta alguns pontos interessantes para reflexão. O primeiro, tocante à inserção econômica e social do leitor, o revela como um sujeito que não tem nenhum acesso a certos bens culturais, especificamente aos que estariam sendo oferecidos aos 
destinatários do LMC, como os textos literários, por exemplo. Ao afirmar e generalizar esse não acesso, o MEC desconsidera, até mesmo, a experiência que esses leitores vivenciaram com o texto literário na escola, nem que tenha sido apenas através do livro didático, ou seja, uma generalização como essa "só faz sentido se imaginar que estamos diante de uma tábula rasa, de um país sem leitores.” (ABREU, 2001, p. 150).

No entanto, talvez essa ausência que o MEC tanto aponta seja a do contato não exatamente com o texto literário, mas com esse texto amparado por um suporte que não seja o livro didático, ou seja, a ausência do livro mesmo de literatura. Textos, ou muito comumente, fragmentos de textos, lidos e trabalhados nas aulas de Português, através do livro didático, são bem comuns no universo infantil, mas o contato com o livro de literatura, realmente, é menos recorrente. Se adentrarmos nos espaços em que esse contato poderia acontecer, percebemos que neles ou há o objeto, mas não o leitor, ou abriga o leitor, mas não possui o objeto. Justificamos essa consideração com imagens de bibliotecas públicas quase vazias, da quase inexistência de bibliotecas particulares, de salas de aula amontoadas de alunos e nenhum livro literário, da parca existência de livrarias no território brasileiro e do alto preço do livro, que restringe a frequência a esses locais a alguns poucos privilegiados; enfim, há uma série de desencontros entre livros e leitores e, consequentemente, menos espaço para a leitura.

Esse quadro social a respeito da tríade "livro, leitor, leitura" já nos permite retomar uma outra reflexão, aquela que diz respeito à distribuição desigual da cultura e que interroga até que ponto um maior contato com certos bens culturais, como a leitura, significa uma maior participação na sociedade letrada, como o MEC acredita e expõe ser uma das razões de suas ações em prol da democratização do livro e da leitura.

Ao levantarmos essa reflexão, estamos adentrando em uma relação considerada, por muitos, como uma espécie de causa e efeito: estamos falando da relação leitura e cidadania ou, ainda, estamos pensando no quanto a expressão formação do leitor tem da expressão formação do cidadão. No cenário de pesquisas sobre a leitura no Brasil, temos Luiz Percival Leme de Britto como um dos professores/ pesquisadores que mais tem refletido sobre a questão, e é dialogando 
com alguns dos seus textos, em especial Sociedade de cultura escrita, alfabetismo e participação (BRITO, 2003a), Implicações éticas e políticas no ensino e na promoção da leitura (2003b) e Leitura e política (1999), que iremos iniciar nossa reflexão.

Logo no inicio do primeiro texto citado acima, Britto (2003, p. 47) "joga" uma interrogativa interessante:

[...] de que maneira e com que intensidade as pessoas dos diferentes segmentos sociais, em função das habilidades de leitura e de escrita que desenvolvem no processo de escolarização e em outras práticas sociais, participam da e usufruem a produção material e cultural da sociedade em que vivem?

Comumente, se costuma pensar que as habilidades de leitura e de escrita são fatores determinantes para a ascensão social e econômica de um indivíduo, sendo esta uma das razões da proliferação de tantas campanhas em prol da alfabetização e da promoção da leitura. Sem jamais diminuir a importância dessas habilidades para a vida cotidiana das pessoas e para o seu desenvolvimento intelectual e cognitivo, podemos dizer, pelo menos, que não necessariamente isso se traduz numa fórmula matemática inquestionável, ou seja, não necessariamente uma pessoa que lê mais e escreve melhor terá sua ascensão social garantida, fará parte, numa posição privilegiada, da sociedade urbanoindustrial. Primeiro, porque o usufruto que se obtém da leitura depende da maneira como se lê e "as possibilidades e formas de ler estão sobredeterminadas pelas formas gerais de educação e de participação social" (BRITTO, 2003b, p. 136), ou seja, não podemos desconsiderar a historicidade do ato de ler, o fato de que o leitor é um sujeito históricosocial e essa sua condição não é apagada no momento da leitura. Britto (2003a, p. 56) inverte aquela "fórmula" citada logo acima; baseado em dados fornecidos pelo INAF (Índice Nacional de Alfabetismo Funcional), ele afirma que, mesmo existindo uma correlação direta entre alfabetismo e oportunidades sociais, isso não quer dizer que a oportunidade profissional é consequência imediata do letramento: “[...] a condição de maior ou menor domínio de habilidades de leitura e escrita e o exercício de atividades dessa natureza é antes o resultado da situação social que a possibilidade de maior participação"; por esse 
motivo, formar o leitor, assim como formar o cidadão, exige ações para ampliar a participação popular na vida pública, exige uma mudança na forma mesma de organização social, exige investimentos em educação básica e na qualificação profissional, pois não seriam "as habilidades pressupostas na leitura ou o gosto ou a determinação de ler que promovem a democracia e a participação social; ao contrário, é a possibilidade de participar da sociedade que permite o acesso à leitura" (BRITTO, 2003b, p. 134). Indo ao encontro das proposições de Luiz Percival, Márcia Abreu tece considerações similares quanto à necessidade de transformações mais profundas para que a atuação do governo na formação dos leitores obtenha maiores efeitos. Segundo a referida pesquisadora (2001, p. 156-157):

Se queremos uma sociedade democrática e justa, inclusive do ponto de vista cultural, é fundamental que se alfabetize a população, que existam escolas e bibliotecas públicas de qualidade. É preciso que haja emprego e salários decentes. É preciso que não haja fome e que as doenças sejam tratadas. Um desempregado, um faminto, não pode se interessar pela "viagem" proporcionada pelos livros, pelo conhecimento de si e do mundo proporcionado pela alta literatura. É preciso que as pessoas tenham condições materiais para ser leitores.

Sob esse ponto de vista, disseminar cultura, como objetivava o MEC com o LMC, não poderia significar, apenas, distribuir livros; cinco livros, a quantidade que era distribuída através do LMC, não formam leitores, e para que houvesse uma interferência maior na formação destes seria preciso ações além das que são objetivadas por um programa de leitura; como comentamos anteriormente, seria preciso transformações profundas na organização social em que vivemos. No entanto, não podemos desmerecer as ações do referido ministério; este tinha consciência tamanha do fato citado que enfatizava em seus textos a necessidade da circulação e de que a escola também assumisse essa luta, não sendo a mera distribuidora das coleções que chegavam para serem entregues aos alunos, mas uma espécie de difusora da cultura e dos valores fundamentais da sociedade (BRASIL, 2003). 
Ao citarmos esses papéis concedidos à escola, recuperamos outro ponto anunciado anteriormente, na citação de um trecho do edital, como interessante para ser alvo de reflexão. Estamos falando no caráter pedagógico que o MEC apontava como sendo inevitável em uma ação como o LMC, pois, segundo ele, era a primeira oportunidade, para muitos brasileiros, de contato com o texto literário. Se este é "fundamental para o desenvolvimento da percepção estética e das referências culturais e éticas do cidadão [...] como forma de expressão artística e cultural, é um patrimônio que deve ser protegido e difundido" (BRASIL, 2003, p. 16-17).

Essa importância e o fato de, provavelmente, poder possibilitar o primeiro contato de muitos leitores com uma obra de literatura, como acreditava o MEC, constituíram a justificativa para todo o cuidado que o ministério empreendeu em escolher os textos "certos", textos que pudessem ser referência cultural, ética e pedagógica para o leitor em gestação. Além de tudo, não se estava lidando com qualquer tipo de público, mas, especialmente, com leitores que ainda se encontravam em formação escolar, a maioria, certamente, crianças, já que, em seus três anos de existência, o LMC privilegiou os alunos de $4^{\mathrm{a}}$ série. E a literatura destinada a esse público infantil sempre foi alvo de uma polêmica que gira em torno de sua natureza específica: ela pertenceria à arte literária ou à arte pedagógica? Segundo Nelly Novaes Coelho, essa controvérsia vem de longe:

[...] tem raízes na Antiguidade Clássica, desde quando se discute a natureza da própria literatura (utile ou dulce? Isto é, didática ou lúdica?) e, na mesma linha, se põe em questão a finalidade destinada aos pequenos. Instruir ou divertir? Eis o problema que está longe de ser resolvido. As opiniões divergem e em certas épocas se radicalizam. (COELHO, 2003, p. 46)

Ainda segundo Coelho (2003), em épocas de consolidação de um determinado sistema, o caráter pedagógico se impõe devido à necessidade de se transmitir valores para serem incorporados pelas novas gerações, a exemplo da literatura romântica, que, na luta pela consolidação do sistema liberal-burguês, impõe a todos uma literatura exemplar, cheia de fórmulas. No entanto, apesar da predominância de 
um ou outro pólo em determinadas épocas, como resultado do próprio momento histórico-social, o que houve e há é a oscilação desses pólos. A produção contemporânea para crianças e jovens, por exemplo, consegue equacioná-los: "literatura para divertir, dar prazer, emocionar...e que, ao mesmo tempo, ensina modos novos de ver o mundo, de viver, pensar, reagir, criar...." (COELHO, 2003, p. 49).

A concepção de literatura que o MEC deixa entrever nos editais revela justamente uma oscilação entre esses dois pólos, isto é, mesmo tentando desvincular o uso das coleções ao didatismo a que elas provavelmente iriam ser submetidas caso estivessem vinculadas ao trabalho escolar, o caráter pedagógico é explicitamente assumido, em especial quando se fala em valores culturais e éticos que devem ser propagados. Se, por um lado, o MEC demonstra uma notória preocupação em não didatizar os textos veiculados nas coleções, e isso fica muito claro quando, no tópico sobre o projeto editorial, posterior à sugestão de que sejam oferecidas informações adicionais relevantes (glossário, notas explicativas, informações históricas, bibliografia), é logo exposto um alerta para que essas informações não didatizassem o texto, nem ocupassem um espaço maior, em tamanho ou destaque, do que o mesmo, afinal a coleção não seria uma "obra didática" (BRASIL, 2003, p. 19), por outro lado, como apontamos, existia o desejo e a preocupação de propagar certos valores culturais e éticos que, na realidade, estão atrelados a uma concepção elitista de literatura, revelada, em especial, nos critérios de seleção das coleções, no padrão de "qualidade" tomado pelo MEC para conduzir a produção/seleção dessas coleções.

No decorrer da exposição desses critérios, dois aspectos, que muito contribuem para fazer entender o que seria essa qualidade e esses valores perseguidos pelo MEC, chamam a atenção. $O$ primeiro diz respeito ao amplo espaço cedido, no edital, às prováveis expectativas e interesses do leitor. Em diversos momentos do referido documento, apela-se para que se priorizem temas de interesse do público ao qual se destinam as coleções, mas também outros que despertem novos interesses e novas referências culturais, que a textualidade das obras se paute "não apenas nas expectativas atuais a respeito da recepção literária do público, mas também na ampliação dessas expectativas" (BRASIL, 2003, p. 20), ou seja, uma preocupação que oscila entre o desejo de 
agradar, de fornecer textos que, seguramente, despertem o prazer no leitor e uma busca para que este amplie seus horizontes por intermédio da leitura.

Atrelado a esses "novos horizontes", mais do que às expectativas reais do leitor, o MEC iria propagar aqueles valores culturais e éticos a que temos nos referido. Acreditamos nisso porque a literatura que o público infantil e juvenil aprecia e desenvolve com mais frequência em seu cotidiano é a de história em quadrinhos, ficção científica, os bestsellers do momento, já os valores a serem propagados por um programa que pretende disseminar a cultura, fazer conhecer o patrimônio cultural brasileiro, estaria, sobretudo, nos clássicos, nos textos e autores canônicos.

Duas observações a respeito do que afirmamos acima precisam ser feitas. A primeira merece ser desenvolvida para que não incorramos no erro de pensar que, já que o MEC não levou em consideração os gêneros preferidos pelo público infanto-juvenil, o desejo de atender às expectativas deste só ficou no papel ou, mais apropriadamente, ele se contradisse ao explicitar esse desejo e não abrir espaço, nos volumes que formariam as coleções, para esses gêneros. Na verdade, as expectativas que o MEC pede para serem cumpridas dizem respeito a temáticas, à textualidade, para que sejam diversificadas, exatamente para que se pudesse atingir interesses e gostos diversos, bem como diferentes contextos sociais, culturais e históricos; postura que mostra que o MEC é consciente da diversidade do público leitor, tanto dessa diversidade de gostos quanto da diversidade de faixa etária e de contexto social. Chega-se mesmo a ser traçado, em certo ponto do edital, um rápido perfil sócio-cultural desse público, onde, além das diversidades já citadas, também é pensada a diversidade quanto à maturação intelectual, à experiência de vida, bem como é apontada a pouca experiência dos leitores com o texto literário.

A outra observação pretende explicar a afirmação que fizemos sobre o fato de que os valores que o MEC pretendia disseminar estariam nos clássicos, nos textos e autores consagrados. Com o intuito de iniciá-la, citaremos as duas espécies de palavras-chave que o MEC impôs como critérios de seleção das coleções e a relação existente entre ambas: a diversidade e a representatividade. 
O MEC tinha o objetivo de oferecer aos leitores o patrimônio cultural brasileiro e, para que esse objetivo pudesse ser concretizado dentro da maior amplitude possível, fazia-se necessário que as coleções abrigassem textos e autores de diversas épocas literárias e de diversas regiões. De acordo com o que consta no edital, os autores deveriam ser escolhidos segundo a representatividade que tivessem dentro da cena cultural brasileira, devendo ser conhecidos e assumidos como referência para a cultura nacional, já os textos deveriam ser representativos de diferentes quadros de referência, "favorecendo a experiência estética diversificada e o desenvolvimento da leitura" (BRASIL, 2003, p. 20).

Tudo isso aponta para uma literatura que é aquela já solidificada pela crítica e pela história da literatura, inclusive aquela veiculada pelo livro didático, ou seja, a literatura dos autores e textos consagrados, integrantes do seleto grupo pertencente ao cânone. Uma literatura que não costuma ser a que os leitores apreciam para ler nas horas de lazer, mas aquela que eles quase sempre associam ao didatismo e ao autoritarismo da sala de aula.

Dentro da escola ou fora dela, sempre foi essa literatura canônica, a "grande" literatura, bem recebida pelas instâncias autorizadas, que foi alvo de esforços em prol da disseminação de sua leitura. Isso só ocorre porque essas instâncias que a legitimam e/ou procuram democratizar o seu acesso veem nela valores culturais e, em especial quando se trata de sua democratização entre o público infanto-juvenil, valores éticos, que precisam ser divulgados e assimilados.

Para entendermos com mais precisão quais são esses valores que o MEC objetivava divulgar através do LMC, é necessário adentrar em um campo teórico escorregadio, alvo de acirradas disputas ideológicas: o da concepção de literatura e de outros termos a ela vinculados, como literariedade e qualidade estética.

Márcia Abreu (2004), em Cultura letrada, literatura e leitura, tece algumas considerações interessantes em relação aos referidos termos. Contrariando a ideia de que a literariedade de um texto está presente apenas nos elementos intrínsecos a ele, defende a posição de que não é, apenas, o valor interno à obra que a consagra, mas também elementos externos ao texto. Vejamos palavras suas capazes de expressar bem o que estamos discutindo: 
O modo de organizar o texto, o emprego de certa linguagem, a adesão a uma convenção contribuem para que algo seja considerado literário. Mas esses elementos não bastam. A literariedade vem também de elementos externos ao texto, como nome do autor, mercado editorial, grupo cultural, critérios críticos em vigor. (ABREU, 2004, p. 41)

Observando os critérios de seleção das coleções expostos pelo MEC, percebemos que esses "elementos externos" são postos em caráter de grande relevância, em especial o do "nome do autor". A representatividade que o autor teria dentro da cultura nacional seria um dos fatores que pesaria no processo de escolha das coleções. Basta olharmos a lista com os nomes dos autores e obras selecionadas para comprovarmos essa afirmação. Nos volumes de poesia, por exemplo, em quase todas as antologias de autores diversos, repetem-se nomes consagrados, como o de Casimiro de Abreu, Álvares de Azevedo, Carlos Drummond de Andrade, Olavo Bilac, Manuel Bandeira, Ana Maria Machado. Analisemos os quadros referentes às coleções distribuídas aos alunos de $4^{a}$ serie nos três anos do LMC, em especial os títulos de poesia.

Todas as nossas observações em relação aos referidos quadros giram em torno das questões da diversidade e da representatividade, tão expostas nos editais elaborados pelo MEC. Em primeiro lugar, analisando o nome das editoras que tiveram suas coleções selecionadas para integrar o LMC, o que percebemos é uma concentração de editoras de grande porte. Nomes como Companhia das Letrinhas, Objetiva e Moderna aparecem nos três anos do LMC. No entanto, apesar de a cada ano ter havido um aumento no número de editoras participantes (no primeiro foram apenas 6 , no segundo foram 8 e no terceiro, 17), fruto mesmo do aumento do número das coleções e das séries que seriam contempladas, já que no terceiro ano os alunos da 8 a série e do EJA também foram alvo do programa, o espaço não foi aberto para editoras menores.

Ao tecermos essas considerações, não estamos duvidando da honestidade e da transparência do MEC no trato com as editoras. O que queremos mostrar, na verdade, é que a presença de algumas poucas editoras é mais um aspecto que nos faz repensar se, de fato, foi 
democrático, como a todo tempo o MEC esteve tentando provar, o processo de seleção das coleções, bem como se a diversidade esteve mesmo presente como uma das características mais marcantes do programa. Recordemos que a intenção era produzir coleções cujos autores e textos fossem representativos de diversas épocas literárias e de diversas regiões e "conhecidos e assumidos como referências da cultura brasileira” (BRASIL, 2003, p. 20).

No caso dos autores e dos textos de poesia, verificamos uma concentração nos modernistas e contemporâneos, apesar de alguns de épocas anteriores também terem encontrado espaço nas antologias, em especial os românticos, a exemplo de Gonçalves Dias, Casimiro de Abreu e Álvares de Azevedo. Os autores que têm volumes inteiros dedicados a si são, por exemplo, do modernismo e da contemporaneidade, a exemplo de Vinícius de Moraes, com sua famosa obra infantil Arca de Noé, Carlos Drummond de Andrade, que teve poemas seus reunidos no volume Simplesmente Drummond, Roseana Murray, com $A$ bailarina e outros poemas. De outros estilos de época, encontramos apenas como presença constante Olavo Bilac, cuja obra Poesias Infantis, lançada em 1910, é considerada pioneira na área da literatura feita para crianças no Brasil; fato que vai ao encontro da exigência do MEC de ter autores que fossem referência para a cultura nacional e que, por si, só justificaria a sua maciça presença nas antologias poéticas do LMC.

Arriscamos lançar hipóteses para justificar a presença de autores mais contemporâneos, hipóteses que giram em torno da linguagem e das expectativas e interesses do público mirim. Por possuir, mesmo que ao tecer esse comentário estejamos correndo o risco de homogeneizarmos uma produção tão heterogênea como é a contemporânea, uma linguagem mais sintética, mais cotidiana, ou seja, mais próxima do público atual, a literatura de autores modernistas e contemporâneos seria mais adequada aos gostos e interesses dos leitores de hoje, em especial do público infantil; ainda mais quando se supõe, como o MEC supunha, que esse público não tivesse quase nenhum contato com o texto literário. O mesmo aconteceria com a poesia romântica, que também ocupa um bom espaço nas antologias do LMC. Como expõe Ana Maria Machado, no prefácio de um dos livros de poesia do LMC, o Cinco Estrelas, a literatura romântica causou 
"uma verdadeira revolução em relação à literatura dos tempos anteriores, muito cheia de regras" (MACHADO, 2001, p. 11). Em meio a todas as ideias de liberdade e independência arraigadas no seio das antigas colônias europeias na América, entre elas o Brasil, era preciso uma linguagem mais simples, que conseguisse discutir com o público todas essas ideias sociais e políticas. Em acordo com uma nova linguagem, novas temáticas começaram a configurar espaço na literatura brasileira, entre elas uma "que até hoje continua sendo muito importante para nós: o que é ser brasileiro?” (MACHADO, 2001, p. 11).

As referidas palavras de Ana Maria Machado justificam a presença da literatura romântica não apenas pelo caráter revolucionário que ela traz em termos de conteúdo e linguagem, mas também por veicular uma questão que se apresenta como um valor essencial: a da identidade nacional. Não podemos esquecer que uma das razões que o MEC usa como justificativa para a realização do LMC é justamente possibilitar, através da leitura do texto literário, o desenvolvimento das referências culturais e éticas do cidadão, e a questão da identidade nacional se apresentaria como um ponto primordial.

Essa questão da identidade nacional é evidenciada, em especial, pela preocupação em oferecer textos representativos de diversas regiões e de diversas realidades histórico-culturais do Brasil, isto é, há a preocupação de mostrar o patrimônio cultural brasileiro em sua totalidade/diversidade, abarcando, inclusive, como um dos volumes das coleções, textos da tradição popular brasileira.

Outro aspecto que nos chamou a atenção nos volumes de poesia foi a forte presença de autores e textos que não são especificamente da literatura infanto-juvenil. Os que integram as coleções e são reconhecidos como tais são nomes contemporâneos, como Ana Maria Machado, Roseana Murray, Elias José, Pedro Bandeira, entre outros. Para tal aspecto, encontramos uma explicação histórica, ao mesmo tempo em que, por intermédio dele, chegamos a uma concepção interessante que o MEC mostra ter a respeito da literatura.

A explicação histórica residiria no fato de a literatura infantojuvenil ser um gênero recente. Segundo Arroyo (1990, p. 26), “a literatura infantil como categoria literária, de acordo com a conceituação perfilhada hoje pelos maiores especialistas no assunto...é muito recente...data ela dos fins do século XVII". No caso da literatura infantil brasileira, mais 
especificamente dos textos e autores de poesia, ela só vai se expandir nos primeiros anos do século XX. Era uma produção poética pequena, restrita a poemas lúdicos, quase sempre pueris, e comprometida com a tarefa educativa escolar, "no sentido de contribuir para formar no aluno o futuro cidadão e indivíduo de bons sentimentos. Daí a importância dos recitativos nas festividades patrióticas ou familiares, e a exemplaridade ou a sentimentalidade que caracterizaram tal poesia" (COELHO, 2003, p. 224). Nessa época, os nomes de destaque no gênero eram: Olavo Bilac, Zalina Rolim, Alexina de Magalhães Pinto, Francisca Júlia, Maria Eugênia Celso, entre outros (COELHO, 2003). Dentre estes, os únicos nomes que aparecem em coleções do LMC são os de Bilac e Francisca Júlia; embora só o primeiro seja recorrente ao longo das coleções, justamente o que se consolidou não apenas como escritor de literatura infantil, mas, principalmente, da literatura destinada ao público adulto, e que teve uma atuação bastante efetiva na sociedade da época, tendo estado envolvido em diversas campanhas cívicas e tendo escrito, inclusive, o Hino à Bandeira (MACHADO, 2001).

Sendo assim, como em termos quantitativos e no que concerne ao prestígio junto à critica os autores e textos da literatura adulta ocupavam um espaço bem maior do que os da literatura infantil, não nos surpreende que os primeiros tenham sido selecionados em maior quantidade para compor as coleções do LMC, que tenham sido tomados como patrimônio cultural brasileiro que precisa ser divulgado. Inclusive, até mesmo quando aparecem textos que foram intencionalmente escritos para o público infantil, em sua maioria, são textos de escritores que, primeiramente, são reconhecidos por sua literatura destinada ao público adulto, exemplo de Carlos Drummond, Vinícius de Moraes, Manoel de Barros, Ferreira Gullar, Cecília Meireles e Olavo Bilac, que já havíamos citado.

Se, por um lado, essa oferta não nos surpreende, visto que os autores citados se inserem no seleto quadro daqueles consagrados pela critica brasileira, ou seja, se inserem nos padrões exigidos nos editais do MEC e estão em acordo com uma tradição amparada e consolidada pela escola, a de apresentar, seja através do livro didático, seja através das aulas de história da literatura, obras e autores consagrados, bem aceitos pela crítica e presentes nos compêndios literários, por outro 
lado vemos aí uma concepção de literatura, mais especificamente de literatura destinada ao público infantil, que não se limita aos textos produzidos especificamente para esse público, mas que congrega textos que, a princípio, pela linguagem mais bem elaborada ou pela temática que veiculam, poderiam ser considerados inadequados às crianças e jovens.

Assim, procurando atingir as expectativas de um público amplo, ao mesmo tempo em que desejava ir além delas, o MEC trabalhou com uma concepção ampla de literatura. Amplidão encontrada nos gêneros, nas épocas literárias, na diversidade de textos - tanto nacionais, quanto clássicos universais, traduzidos ou adaptados, tanto textos da literatura destinada ao público adulto quanto textos da literatura destinada ao público infantil. No entanto, é claro que, se formos pensar na diversidade e no caráter democrático que o MEC desejava para o LMC, as coleções deixam a desejar. Quanto aos gêneros, por exemplo, apesar de serem formadas por cinco - uma antologia poética, uma antologia de contos brasileiros, uma novela brasileira, uma obra clássica da literatura universal traduzida ou adaptada, uma peça teatral ou obra ou antologia de textos de tradição popular brasileira - poderíamos lastimar a ausência de gêneros tão apreciados por crianças e jovens, como as histórias em quadrinhos, por exemplo. Por outro lado, temos a inserção da música popular brasileira: nomes como os de Cachaça, Braguinha, João Bosco, Adoniran Barbosa dividem espaço com os dos poetas, e as canções que eles compõem são ofertadas como poemas.

\section{Considerações finais}

A partir de todas as constatações apresentadas, podemos afirmar que a leitura literária que o MEC desejava ofertar está sempre transitando por dois espaços: ao mesmo tempo em que pretende se mostrar em sua diversidade, em sua amplidão - estética, de estilos de época, de temáticas - concentra-se em autores e textos consagrados pelas instâncias autorizadas - a exemplo da critica literária e da escola -, ou seja, autores e textos representativos do que o MEC concebe como patrimônio cultural brasileiro. E, considerando-se a sua suposta função, é investida de um caráter pedagógico explicitamente assumido, em especial quando se pensa nos valores culturais e éticos dos quais ela 
deve ser portadora, mas, por outro lado, é revelado o desejo de que seja efetivada longe de imposições didáticas.

No que concerne ao leitor, devemos lembrar que o MEC revela uma preocupação com suas necessidades e expectativas, bem como com a ampliação dessas expectativas, com a oferta de novos horizontes para esse público, tendo mostrado estar consciente da diversidade dele; até mesmo porque a intenção não era a de que as coleções atingissem apenas os alunos, mas a de que circulassem por outras vias, em especial entre as famílias. Desse modo, não eram apenas crianças e jovens que entrariam em contato com as obras, mas também um público adulto.

Em síntese, podemos afirmar que a história do LMC e as concepções que orientaram o trabalho do MEC e das editoras no processo de elaboração e escolha de suas coleções apontaram, ao mesmo tempo, uma faceta inovadora e outra que está inserida na tradição, pois as concepções que a avaliação dos editais nos mostraram, bem como a da seleção de autores e textos, foram ideias sobre leitura, literatura e leitor que há tempos conduzem os trabalhos em prol da democratização do livro e da leitura no Brasil.

\section{Referências}

ABREU, M. Percursos da leitura. In: Leitura, História e História da Leitura. Campinas: Mercado de Letras, ALB; São Paulo: Fapesp, 2000.

- Diferença e desigualdade: preconceitos em leitura. In: MARINHO, M. (org.). Ler e navegar: espaços e percursos da leitura. Campinas: Mercado Aberto, 2001.

. Letras, Belas-letras, Boas Letras. In: BOLOGNINI, C. Z. (Org.). História da literatura: o discurso fundador. Campinas: Mercado de Letras, ALB; São Paulo: Fapesp, 2003.

ARROYO, L. Literatura infantil brasileira. São Paulo: Melhoramentos, 1990. 
BRASIL. Ministério da Educação. Programa Nacional Biblioteca da Escola PNBE/2003. Brasília-DF, 2003. Disponível em: <http: //www.cbl.org.br/download.php?recid=59>. Acesso em: 23 maio 2006.

BRITTO, L. P. L. de. Leitura e política. In: EVANGELISTA, A. A. et al. A escolarização da leitura literária: o jogo do livro infantil e juvenil. Belo Horizonte: Autêntica, 1999.

Sociedade de cultura escrita, alfabetismo e participação. In: RIBEIRO, V. M. (Org.). Letramento no Brasil. São Paulo: Global, 2003.

Contra o consenso: cultura escrita, educação e participação. Campinas: Mercado de Letras, 2003a.

CHARTIER, R. A ordem dos livros: leitores, autores e bibliotecas na Europa entre os séculos XIV e XVIII. 2. ed. Brasília: Editora UnB, 1999.

COELHO, N. N. A literatura infantil - teoria, análise, didática. São Paulo: Moderna, 2000.

MACHADO, A. M. Poesia: semente de toda a literatura. In: PESSOA, I. Cinco Estrelas. Rio de Janeiro: Objetiva, 2001. (Literatura em minha casa). 